\title{
Comparative study on cervical ripening and labour induction with dinoprostone versus foley's catheter with extra amniotic saline infusion
}

\author{
Rachel Alexander A.*, Gigi A.
}

Department of Obstetrics and Gynaecology, Government TD Medical College, Vandanam, Alappuzha, Kerala, India

Received: 19 July 2020

Accepted: 03 September 2020

\section{*Correspondence:}

Dr. Rachel Alexander A,

E-mail: drrachelalexander@gmail.com

Copyright: (C) the author(s), publisher and licensee Medip Academy. This is an open-access article distributed under the terms of the Creative Commons Attribution Non-Commercial License, which permits unrestricted non-commercial use, distribution, and reproduction in any medium, provided the original work is properly cited.

\begin{abstract}
Background: Induction of labour is defined as initiation of uterine contractions before spontaneous onset of labour. This observational study compares the effect of prostaglandin $\mathrm{E}_{2}$ (PGE2) and extra amniotic saline infusion (EASI) for pre-labour ripening of unfavourable uterine cervix.

Methods: This was a prospective study conducted on 100 pregnant women with gestational age $\geq 37$ weeks during a year period in the department of obstetrics and gynaecology of government TD medical college, Alappuzha, Kerala. The period of study was for one year from June 2002 to July 2003. All patients were divided into two groups. Group1 contains 47 patients who received intracervical $\mathrm{PGE}_{2}$, (Dinoprostone gel, $0.5 \mathrm{mg}$ ). Group-2 contains 53 patients who were induced with EASI. The main outcome variables were the number of subjects with favourable Bishop's score, mode of delivery, maternal complications and neonatal outcomes.

Results: Majority of the patients in both the groups were in the age of 21-30 years. There was significant difference in age, parity and gestational age of both groups. In this study it was found significant difference in the occurrence of hyper stimulation among PGE2 and EASI; whereas, there was no significant difference in the occurrence of maternal pyrexia among two groups. High incidence of caesarean section was found in EASI. APGAR score of new born babies was high in labour induced with PGE2.

Conclusions: PGE2 and EASI have similar efficacy in induction of labour, but EASI is associated with more side effects. Cost wise EASI is more cost effective than PGE2.
\end{abstract}

Keywords: Cervical ripening, Bishop's score, Extra amniotic saline infusion, Labour induction, Prostaglandin E2

\section{INTRODUCTION}

Induction of labour is defined as initiation of uterine contractions before spontaneous onset of labour. For majority of women labour starts spontaneously and results in vaginal delivery at or near term. However, induction of labour is required when there is risk of continuation of pregnancy either to the mother or to the foetus. The purpose of cervical ripening and induction of labour is to achieve vaginal delivery and to avoid operative delivery by caesarean section. A successful labour induction must result in adequate uterine contractions and progressive dilatation of cervix. ${ }^{1}$ It should also result in vaginal delivery, as there is little purpose in bringing about labour as a mere preparation for caesarean section. Labour induction should be carried out with minimum discomfort and risk to both mother and foetus. ${ }^{2}$

The two means of cervical ripening prior to labour induction are pharmacological methods and nonpharmacologic methods. Pharmacological methods consist of prostaglandins and they are capable of stimulating uterine contractions resulting in labour. Prostaglandins can be administered by various routes: 
vaginal, oral and intracervical. ${ }^{3}$ In non-pharmacologic methods there are natural and mechanical methods. In natural methods consist of herbal supplements, intercourse, breast stimulation, membrane stripping, amniotomy and the mechanical method consists of Balloon devices, hygroscopic dilators, acupuncture. Mechanical device dilates the cervix by accessing the fetal membrane and pharmacological preparation cause connective tissue softening, cervical effacement and uterine activity. ${ }^{4}$ Despite the multiplicity of techniques, there is no universally accepted idea, thus the ideal method of labour induction remains elusive. ${ }^{5}$

Prostaglandins as pharmacological agents are used for induction of labour as well as cervical ripening. The commonly used prostaglandins in obstetrics are prostaglandin E1 (PGE1- Misoprostol) and prostaglandin E2 (PGE2-Dinoprostone). Cervical ripening induced by PGE2 is associated with an increase in inflammatory mediators in the cervix and remodelling of the cervical extracellular matrix through a decrease in collagen cross links and increase in cervical glycosaminoglycan. ${ }^{6}$ Dinoprostone is the widely used PGE2 analogue that has been approved by the FDA for cervical ripening in women. PGE2 softens the cervix by altering the extra cellular ground substance of cervix. It increases the activity of collagenase and elastase. Exogenous PGE2 also act on cervical smooth muscle thus facilitating cervical dilatation. PGE2 facilitates gap junction formation thus sensitizing uterus to oxytocin, thereby reducing its subsequent use.

Mechanical dilatation methods comprise of trans-cervical Foley catheter alone and trans-cervical Foley catheter with EASI for enhanced endogenous prostaglandin secretion ${ }^{7}$ Cervical ripening with extra amniotic balloon catheters possess the advantages of simplicity, low cost, reversibility and lack of severe side effects; however ripening with extra amniotic balloons subsequently requires oxytocin augmentation in many cases and is associated with significant rate of dysfunctional labour and caesarean section. The balloon catheter with EASI probably has a place as a cervical ripener, especially when prostaglandins are contra indicated or when uterine hyper stimulation should be avoided such as in cases of fetal IUGR or placental insufficiency. EASI is of low cost, effective and relatively less frequent occurrence of major complications. Studies shows this method can be safely used in patients with previous caesarean section for cervical ripening and labour induction. Different studies conducted so far shows that EASI is as effective as prostaglandins, safe and much cheaper than prostaglandins.

Objectives of the study were the present study was undertaken with the aim to compare the effect of PGE2 and EASI for prelabour ripening of unfavourable uterine cervix in pregnant women. This study also compares the effects of PGE2 and EASI on maternal complications and neonatal outcomes.

\section{METHODS}

\section{Study population}

This study was an observation study conducted at the Department of Obstetrics and Gynaecology (OB and G), Government TD Medical College, Alappuzha. The period of study was for one year from June 2002 to July 2003. The study protocol was approved by the regional committee for medical research ethics. The period of study was for one year. Information was collected from 100 pregnant women who were selected for induction of labour at $\mathrm{MCH}$ Alappuzha $\left(\mathrm{O}_{1}\right.$ unit). All the participants were informed about this research and written consents were obtained from each participant.

\section{Inclusion criteria}

Women admitted to the Department of OB and G who met the following inclusion criteria were selected for this study-Bishop's score $<6$, Unscarred uterus, Singleton pregnancy, Cephalic presentation, Intact membranes and No contraindication for vaginal delivery.

\section{Exclusion criteria}

Pregnant women with the following conditions were excluded from this study.

Previous scar on uterus i.e., previous LSCS, previous myomectomy etc., Patients in active labour i.e. more than $3 \mathrm{~cm}$ dilatation and or having more uterine contractions lasting for more than 30 seconds in ten minutes of observation, Ruptured membranes, Hyper sensitivity to prostaglandins and any serious maternal disease or fetal condition.

General and systemic examination (cardiovascular system and respiratory system) was also performed. All biochemical investigations including blood and urine examinations were done. Baseline parameters were noted. Pre-induction counselling was done. Patients were explained about the need for induction as well as use of the drugs, their safety and adverse effects.

Bishop's score was noted prior to induction (at zero hour). Detailed pelvic examination was done to judge the condition of cervix according to Bishop's score and adequacy of pelvis. An admission fetal non-stress test (NST) was carried out to examine fetal wellbeing. The patients with reactive NST were taken for the study. When NST was reactive, patient was induced with either of the two methods. All pregnant women with Bishop score $<6$ was randomly allotted for induction of labour either with PGE2 or patients whose Bishop Score $<3$ was induced with EASI. ${ }^{8}$ 


\section{Dosage}

All the 100 patients were divided into two groups. Group1 consisted of 47 patients who were received intracervical PGE2, $(0.5 \mathrm{mg})$. PGE2 was instilled with all aseptic precautions to the cervical canal and repeated at the interval of 6 hours to a maximum of three doses. ARM was done once the patient entered the active phase of labour. Group II comprised of 53 patients who were induced with Foley's catheter with EASI.

In Foley's catheter with EASI method of induction, with all aseptic precautions, No.18 Foley's catheter was introduced extra amniotically after visualizing cervix with speculum and clearing with povidone iodine. 50 m1distilled water was used to inflate the bulb. Bulb was pulled and $200 \mathrm{~m} 1$ lukewarm saline was injected extra amniotically one $\mathrm{ml}$ per minute. Foley's catheter removed after $24 \mathrm{hrs}$ and oxytocin drip was started after removal or spontaneous expulsion of the bulb. For this group Ampicillin $2 \mathrm{gm}$ intravenous injection at 6th hourly and Metrogyl 500mg intravenous injection at 8th hourly were given.

Vital parameters of all patients were recorded and per abdomen examination was done one hourly for uterine activity, tachysystole or hyperstimulation. Fetal heart rate was monitored. All patients were reassessed after 6 hours and if required repeat dose kept. Reassessment was also done to note improvement in Bishop's score and progression to active phase. Important anthropometric details were recorded from the patients using a standard questionnaire. To avoid inter observer and instrumental bias; all measurements were taken by the same measuring instrument/scale and by same person.

\section{Statistical analysis}

In this study, the descriptive statistics of the sample population and Chi Square test was carried out to study the association of different methods of labour induction and pregnancy outcomes.

\section{RESULTS}

In the sample of 100 women, 47 women (Group I) were induced with PGE2 and remaining 53 women (Group II) were induced using Foley's catheter with EASI in figure1.
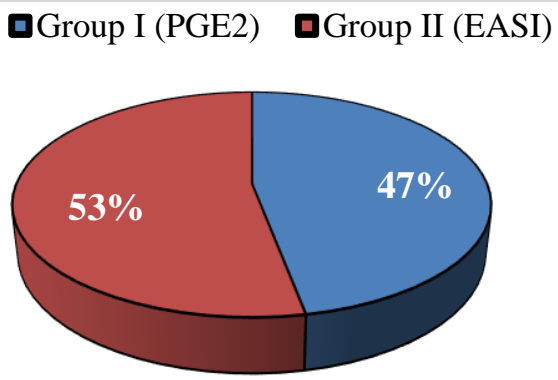

Figure 1: Distribution of women according to method of induction.

Table 1 depicts the maternal demographic profile of the women included in the study. Both groups were comparable with respect to maternal age, parity and mean gestational age at the time of induction. In group I, $12.25 \%$ patients were below the age of 20 years. Maximum numbers of women belonged to the age group of 21 to 30 years in group I and minimum number was found in the age group between 31-40 years. Similar distribution was found in group II. Whereas in group II, women with age less than 20 years, between 21-30 and between $31-40$ were $24.53 \%, 71.70 \%$ and $3.77 \%$ respectively. As p value was less than 0.000 , significant difference was found in the age of both groups. A significant ( $p$ value 0.000 ) difference between the two groups in the case of parity and as well as in gestational age was found in this study.

Table 1: Comparison of demographic variables between PGE2 and EASI groups.

\begin{tabular}{|c|c|c|c|c|}
\hline \multirow{2}{*}{ Indicators } & & PGE2 & EASI & \multirow{2}{*}{ P value } \\
\hline & & Percentage (\%) & Percentage (\%) & \\
\hline \multirow{3}{*}{ Age (years) } & $<=20$ & 12.25 & 24.53 & \multirow{3}{*}{$0.000 * * *$} \\
\hline & $21-30$ & 73.47 & 71.70 & \\
\hline & $31-40$ & 10.20 & 3.77 & \\
\hline \multirow{3}{*}{ Parity } & Primi & 61.22 & 96.23 & \multirow{3}{*}{$0.000 * * *$} \\
\hline & Para 1 & 30.61 & 3.77 & \\
\hline & Para 2 & 4.08 & 0.00 & \\
\hline \multirow{2}{*}{ Gestational age (Weeks) } & Pre term & 4.082 & 18.87 & \multirow[b]{2}{*}{$0.000 * * *$} \\
\hline & Term & 91.84 & 81.13 & \\
\hline
\end{tabular}

Table 2 portrays the oxytocin augmentation in group I and group II. There was significant difference in oxytocin augmentation among two groups.
Most of the women in both groups underwent normal delivery. Caesarean and instrumental delivery was more in group II when compared to group I (table 3). This 
study found significant difference in the mode of delivery among group I and group II.

Analysis of Apgar score was done for all new born. All the babies born in PGE2 group had a higher Apgar score (6-10). None of the babies of group I had Apgar score less than 6 at one minute and after five minutes. Apgar scores are presented in table 4. At one minute, $3.77 \%$ babies had zero Apgar score for group II whereas it was only $0 \%$ in PGE2 group.

Table 5 depicts other maternal complications occurred among group I and group II. In this study the maternal complications considered were hyper stimulation and maternal pyrexia. This study found significant difference in the occurrence of hyper stimulation among PGE2 and EASI; whereas, there was no significant difference in the occurrence of maternal pyrexia among two groups.

Table 2: Comparison of oxytocin augmentation in PGE2 and EASI groups.

\begin{tabular}{|llll|}
\hline Pitocin & PGE2 $(\%)$ & EASI $(\%)$ & P value \\
\hline Yes & 42.55 & 86.79 & \multirow{2}{*}{$0.000 * * *$} \\
\hline No & 57.45 & 13.21 & \\
\hline ***significant at $1 \%$. & & \\
\hline
\end{tabular}

Table 3: Comparison of mode of delivery in PGE2 and EASI groups.

\begin{tabular}{|c|c|c|c|}
\hline Mode of delivery & $\begin{array}{l}\text { PGE2 } \\
(\%)\end{array}$ & $\begin{array}{l}\text { EASI } \\
(\%)\end{array}$ & P value \\
\hline Spontaneous & 68.09 & 62.26 & \multirow[b]{3}{*}{$0.000 * * *$} \\
\hline Caesarean section & 19.15 & 30.19 & \\
\hline $\begin{array}{l}\text { Instrumental } \\
\text { (forceps or } \\
\text { ventouse) }\end{array}$ & 12.77 & 7.55 & \\
\hline
\end{tabular}

Table 4: APGAR scores of PGE2 and EASI groups.

\begin{tabular}{|llll|}
\multirow{2}{*}{ Time } & $\begin{array}{l}\text { APGAR } \\
\text { score }\end{array}$ & PGE2 $(\%)$ & EASI (\%) \\
\hline \multirow{4}{*}{$\begin{array}{l}\text { At one } \\
\text { minute }\end{array}$} & 0 & 0.00 & 3.77 \\
\cline { 2 - 4 } & 4 & 0.00 & 1.89 \\
\cline { 2 - 4 } & 6 & 2.13 & 0.00 \\
\cline { 2 - 4 } & 8 & 0.00 & 1.89 \\
\hline \multirow{3}{*}{$\begin{array}{l}\text { After } \\
\text { five } \\
\text { minutes }\end{array}$} & 9 & 6.38 & 3.77 \\
\cline { 2 - 4 } & 4 & 91.49 & 88.68 \\
\hline & 6 & 0.00 & 3.77 \\
\hline & 9 & 0.00 & 0.00 \\
\hline
\end{tabular}

Table 5: Comparison of maternal complications in PGE2 and EASI groups.

\begin{tabular}{|lclll|}
$\begin{array}{l}\text { Maternal } \\
\text { complications }\end{array}$ & Yes & $\begin{array}{l}\text { PGE2 } \\
(\%)\end{array}$ & $\begin{array}{l}\text { EASI } \\
(\%)\end{array}$ & P value \\
\cline { 1 - 4 } $\begin{array}{l}\text { Hyper } \\
\text { stimulation }\end{array}$ & No & 82.98 & 98.11 & \multirow{2}{*}{$0.000 * *$} \\
\hline $\begin{array}{l}\text { Maternal } \\
\text { pyrexia }\end{array}$ & Yes & 0.00 & 3.77 & \multirow{2}{*}{0.179} \\
\cline { 2 - 4 } & No & 100 & 96.23 & \\
\hline \multirow{2}{*}{ significant at $1 \%}$. & & & \\
\hline
\end{tabular}

Table 6: Comparison of neonatal outcome in PGE2 and EASI groups.

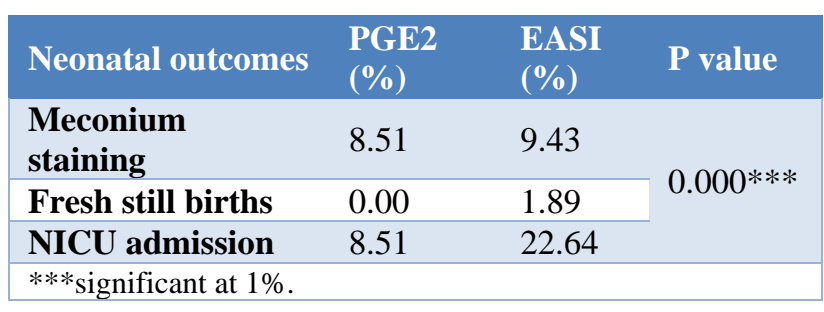

Table 7: Comparison of induction to delivery interval in PGE2 and EASI groups.

\begin{tabular}{|lllll|}
\hline Intervals & Method & Mean & Standard deviation & Std Error \\
\hline Induction delivery interval & PGE2 & 720.15 & 685.42 & 94.1 \\
\cline { 2 - 5 } & EASI & 1655.13 & 668.41 & 40.02 \\
\hline Rupture of membrane delivery & PGE2 & 240.96 & 186.04 & 27.14 \\
\hline interval & EASI & 333.84 & 232.87 & 32.29 \\
\hline
\end{tabular}

The neonatal outcomes are depicted in table 6. Meconium staining was found higher in EASI group. There were no fresh still births in group I. Meconium staining fresh still births and NICU admission was higher in group II. There was significant difference between two groups with regard to neonatal outcomes.

The interval between labour induction and delivery is given in table 7 . For PGE2 group the mean induction delivery interval was 720.15 minutes where as it was quite high for EASI method. The rupture of membrane delivery interval was also found high in EASI method.
The mean induction delivery interval was less for PGE2 (minimum-185 minutes and maximum-3050 minutes) when compared to EASI (minimum-461 minutes and maximum-3480 minutes).

\section{DISCUSSION}

Labour induction is one of the most commonly performed obstetric procedures in patients undergoing inpatient cervical ripening. Recently, induction of labour by use of prostaglandins are very common due to a rise in indications for maternal and fetal reasons. ${ }^{9}$ Induction of 
labour with prostaglandins offers the advantage of promoting both cervical ripening and myometrial contractility. A drawback of prostaglandin is their ability to induce excessive uterine contractility which can increase perinatal morbidity. ${ }^{10}$ Prostaglandins are highly efficacious cervical ripening agents used to shorten induction to delivery intervals, improve induction success, and reduce morbidities associated with prolonged labour induction. EASI is successful in inducing labour in antepartum fetal deaths after 20 weeks of gestation. This method has been shown to be safe and well tolerated by the women and should be considered in areas with limited resources. ${ }^{11}$

In this study a sample size of 100 cases were taken. Out of the total samples, 47 cases were induced with PGE2 (group I) and rest 53 were induced with EASI (group II). The baseline characteristics taken in the study were age, parity and gestational age. Among the three baseline characteristics, significant difference in age, parity and gestational age between two groups was found. The study of Acharya et al. (2017) conveyed that oxytocin is an effective method of labour induction. ${ }^{12}$ The present study indicates that $\mathrm{PGE}_{2}$ was associated with less oxytocin augmentation when compared to EASI method of labour induction. Pregnant women with very unfavourable cervix $(\mathrm{BS} \leq 3)$ are selected for EASI method of labour induction. Therefore, EASI alone may not be sufficient for a successful delivery. So high percentage of oxytocin augmentation is required for women in group II. ${ }^{13}$ Sanchez-Ramos et al. concluded that the increase in the dose of PGE2 gel did not increase the possibility of a vaginal delivery, but reduced the requirement for oxytocin while increasing hypertonic uterine action. ${ }^{14}$

In all methods of induction there is chance of failed induction. No method will offer $100 \%$ chance of spontaneous delivery. Caesarean section is high in EASI group because failed induction rate is more in EASI method of labour induction due to unfavourable cervix at the onset of induction. Hyperstimulation is a side effect of pharmacological methods. That is the reason for hyperstimulation in PGE2. As EASI is a mechanical method of labour induction, side effect like hyperstimulation is less in EASI method. As EASI is an invasive method, chance of introducing infection is more even if it is done under strict aseptic precautions. Due to this maternal pyrexia is high in group II. In PGE2 group less chance of infection if strict aseptic precautions are maintained. APGAR score is a 10-point scoring system to assess the newborn wellbeing. Scores at one minute and five minutes are assessed for the new born baby. If the score is high, survival of the baby is high. High per cent of NICU admission was found in group II. This was due to increased meconium stained amniotic fluid in this group. Prostaglandins including a variety of classes, doses and routes of administration, have been widely studied as alternatives to oxytocin. ${ }^{15-17}$ Induction of labour with prostaglandins offers the advantage of promoting both cervical ripening and myometrial contractility. A drawback of PGs is their ability to induce excessive uterine contractility which can increase perinatal morbidity. ${ }^{18}$

Failed induction rate of PGE2 was $2.13 \%$ where as it was high in EASI (15\%). BS remained $\leq 6$ even after $12 \mathrm{hrs}$ is considered as failed induction for PGE2 group. In the EASI group failure rate is calculated as inability to achieve $\mathrm{BS} \geq 4$ when Foley expels/removed. PGE2 induction cost is high when compared to EASI. Foley's catheter with EASI as a method of induction of labour should be considered in areas with limited resources. According to Mohamed K and Jayaguru AS, Zimbabwe, in a study of EASI for induction of labour in antepartum fetal death: a cost-effective method worthy of wider use. $^{19}$

\section{CONCLUSION}

Present study investigated the comparison between PGE2 and EASI in labour induction. This study used Chi-square test to estimate the association of PGE2 and EASI with maternal complications and neonatal outcomes. This study proved that PGE2 and EASI had similar efficacy in induction of labour. In very unfavourable cervices $(\mathrm{BS}<3)$ Foley's catheter with EASI is better than PGE2 method of induction especially in areas with limited resources. Nevertheless, this study had limited number of patients, and being a small-scale study, further studies involving large samples comparable to those done in Western countries are recommended. Precise use of induction agents with careful selection of patients can be a useful method to reduce the perinatal morbidity and mortality.

Funding: No funding sources

Conflict of interest: None declared

Ethical approval: The study was approved by the Institutional Ethics Committee

\section{REFERENCES}

1. Gupta S, Hak J, Kumar D. Comparative Study of Efficacy of Misoprostol vs Dinoprostone Gel for Induction of Labour. Jkscience. 2016;17(3):118-22.

2. Ramya D. Jaju PB. Comparative Study of IntraVaginal Misoprostol with Intra-Cervical Dinoprostone Gel for Induction of Labour. Obstet Gynecol Int J. 2017;6(5):00223.

3. Chodankar R. Sood A. Gupta J. An overview of the past, current and future trends for cervical ripening in induction of labour. Obst Gynaecol. 2017;19(3):219-26.

4. Joan Crane. St Jhon's N F. Line L. Gregory JR. Induction of labour at term. J Obstet Gynecol Can. 2001;23:717-28.

5. McEwan AS. Induction of labour. Obstet Gynecol Reprod Med. 2008;18:1-6.

6. Ghanaie MM. Jafarabadi M. Milani F. Asgary SA. Karkan MF. A randomized controlled trial of foley 
catheter, extra-amniotic saline infusion and prostaglandin e2 suppository for labor induction. J Fam Reprod Health. 2013;7(2):49-55.

7. Niromanesh S. Mosavi-Jarrahi A. Samkhaniani F. Intracervical Foley catheter balloon vs. prostaglandin in preinduction cervical ripening. Int $\mathbf{J}$ Gynecol Obstet. 2003;81(1):23-7.

8. Laughon SK, Zhang J, Troendle J, Sun L, Reddy UM. Using a simplified Bishop score to predict vaginal delivery. Obstet Gynecol. 2011;117(4):80511

9. Day ML. Snell B J. Use of prostaglandins for induction of labor. Journal of Nurse-Midwifery. 1993;38(2):S42-8.

10. Keirse MJNC. Prostaglandins in preinduction cervical ripening. Metanalysis of worldwide clinical experience. J Reported Med. 1993;38(1):89-98.

11. Danielian P. Porter B. Ferri N. Summers J. Templeton A. Misoprostol for induction of labor at term: a more effective agent than dinoprostone vaginal gel. Bri J Obstet Gynaecol. 1999;106(8):793-7.

12. Acharya T, Devkota R, Bhattarai B, Acharya R. Outcome of misoprostol and oxytocin in induction of labour. SAGE open medicine. 2017:5.

13. Tabor B, Anderson J, Stettler B, Wetwiska T. Misoprostol Vs PGE2 gel for cervical ripening. Am J Obs Gynaeco1. 1995;172:425.
14. Sanchez-Ramos L, Peterson DE, Delke I, Gaudier FL, Kaunitz AM. Labor induction with prostaglandin El misoprostol compared with dinoprostone vaginal insert: A randomized trial. Obstet Gynecol. 1998;91:401-5.

15. Macer J, Buchanan D, Youakura MC. Induction of labour with PGE, vag suppositories. Obst Gynaecol. 1984;63:664-668

16. Gordon-Wright AP. Elder M G. PGE, tablets used intravaginally for the induction of labour. Obstet Gynaecol. 1979;86:32-6.

17. Craft I. Amniotomy and the oral PGE2 titration for induction of labour. Bri Med J. 1972;2:191-4

18. Keirse MJNC. Prostaglandins in preinduction cervical ripening. Metanalysis of worldwide clinical experience. J Reported Med. 1993;38(1):89-98.

19. Mahomed K, Jayaguru AS. Extra-amniotic saline infusion for induction of labour in antepartum fetal death: a cost-effective method worthy of wider use. Bri J Obstet Gynaecol. 1997;104(9):1058-61.

Cite this article as: Alexander AR, Gigi A. Comparative study on cervical ripening and labour induction with dinoprostone versus foley's catheter with extra amniotic saline infusion. Int J Reprod Contracept Obstet Gynecol 2020;9:4080-5. 